\title{
OBITUÁRIO ONTEM E HOJE: DO BIOGRÁFICO FAST FOOD A UMA “LITERATURA DE JORNAL”
}

\author{
Willian Vieira* \\ Universidade de São Paulo \\ São Paulo, São Paulo, BR
}

\section{Resumo}

Este artigo oferece um panorama do fenômeno cultural de publicação e leitura de obituários em jornais de língua inglesa e nas coletâneas deles oriundas. A partir daí, relaciona o surgimento desse gênero específico e sua manutenção hegemônica nos jornais ingleses e americanos com o caráter biográfico, instantâneo e literário de sua narrativa. Para compreender o interesse extemporâneo por um gênero que migra da efemeridade do jornal para as coletâneas, analisa-se sua conformação romanesca, decantada a partir de outros gêneros e formada pela confluência entre temas de vida e morte marcada pelo suplemento de verdade do discurso da imprensa. Tal gênero apelaria esteticamente ao leitor por poder ser fruído, ao mesmo tempo, como relato de verdade eticamente rico e como uma espécie acessível e iterativa de literatura.

Palavras-chave: Obituário; Coletânea; Estudos Culturais; Imprensa; Literatura

\section{OBITUARIES, PAST AND PRESENT: FROM THE FAST FOOD BIOGRAPHICAL NARRATIVE TO A "NEWSPAPER LITERATURE"}

\begin{abstract}
This article offers a panorama of the cultural phenomena of obituary publishing and reading, both on newspapers in English, their original locus, and anthologies. It relates the appearance of this specific genre and its hegemonic lasting in contemporary American and British newspapers to the biographical, instantaneous and literary aspects of its narrative. The reasons for the extemporaneous interest of the reader in a genre that often migrates from the ephemerality of newspapers to long-lasting print anthologies is searched for in its romanesque configuration, itself originated from other genres and formed by discourses of life and death, ultimately legitimized by the truth discourse of the Press. Hence, the obituary would be consumed, esthetically, both as an ethically profound true story and as easy literature.
\end{abstract}

Keywords: Obituary; Anthology; Cultural Studies; Press; Literature

No capítulo "Quant au livre", de Divagations, Mallarmé (2003) opunha o caráter de produção e leitura do texto publicado no jornal aos do livro: o último, transcendental, superior, seria o espaço natural da literatura, enquanto o primeiro seguiria restrito às politicagens do cotidiano. No volume, dizia, haveria interioridade, algo de sagrado, enquanto na efemeridade do periódico, apenas superficialidade e exposição pública. Claro, uma aproximação histórica ajuda a entender a radicalidade da distinção: a Europa vivia então um boom da literatura dita comercial, assim como o florescer da imprensa, sobretudo com os folhetins. Era desses últimos, aliás, que emergia a fluidez dessa literatura acessível à avidez das massas. Ao ganhar espaço, a imprensa ameaçava a supremacia das belas letras na formação da opinião pública.

Mais que um causo dos anais da literatura, porém, tal história ilustra o debate que segue. Pois parece ser mais que coincidência o fato de, justamente no período em que Mallarmé vociferava contra a imprensa, na segunda metade do século XIX, os obituários terem 
surgido nos jornais, e já com clareza genérica, na vizinha Inglaterra - para logo ganharem a formatação burilada de perfis biográficos e, anos depois, justamente o abrigo interior, superior e transcendental das coletâneas em volume.

Uma primeira investigação, histórica, da emergência dos obituários explicará tal consonância. A imprensa, ao ceder terreno ao interesse pelo romanesco cotidiano, daria vazão a novos anseios entre os leitores, a ser satisfeitos pela nascente literatura romântica, de início, mas logo pelo obituário. Uma segunda análise, formal e cultural, lançará luz sobre como tais textos, advindos da confluência entre biografia e ritos fúnebres, estilos textuais típicos da literatura e das narrativas mortuárias - além do regime discursivo certificado pelo estatuto de verdade do jornalismo - continuam suprindo um horizonte de expectativa que os mantém vivos como gênero. Um gênero que, ver-se-á por último, detém uma conformação que permite uma fruição de tipo literário, sobretudo a partir do formato físico das coletâneas.

\section{Dos primórdios à conformação genérica: morte, fama, folhetins}

Muito se debateu sobre as origens do obituário. Fowler (2007) vê o ano de 1731 como marco do surgimento do gênero, no londrino The Gentleman's Magazine, que dava espaço a perfis biográfico-mortuários de figuras conhecidas e desconhecidas. Um século depois, o hegemônico The Times, que já se destacava como porta-voz da elite do império em ascensão, publicava -os em seção fixa, diariamente. Assim, no fim do século XIX, os obituários já eram tão bem vistos na Inglaterra a ponto de merecerem espaço fixo no jornal mais eminente do reino.

Tal emergência, segundo Fowler, teria relação com o surgimento de uma cultura da esfera pública e com a formação de um público leitor e frequentador de cafés, onde os jornais, onipresentes, orientavam discussões, ao menos entre uma elite ilustrada masculina. Foi assim que, com a consolidação da imprensa no século XIX, o obituário tornou-se um gênero específico nos países de língua inglesa.
Enquanto Mallarmé dizia que um verso poderia ser encontrado em qualquer lugar, "excepte dans les affiches et à la quatrieme page des journaux" (apud BLANC, 1998, p. 414), a imprensa ganhava espaço por cedê-lo a novos temas e formas: fofocas, assassinatos, escândalos. É quando se desenha uma relação íntima entre fama e morte na imprensa. Ao analisar obituários de dois jornais da Inglaterra do século XIX (The Post-Angel e The Gentleman's Magazine), Barry (2008) conclui que o interesse massivo pela vida pessoal de quem hoje chamaríamos de celebridades surge com a consolidação da imprensa e o acesso barato a narrativas como os obituários:

Fame and death found a new relationship in this period, the huge expansion of popular print journalism in the late eighteenth century bringing with it the possibility that almost anyone might find a form of secular immortality in print and image. The other side of the coin was that weak libel laws also allowed the press to freely indulge its readers' interest in the private lives of prominent figures, even after their deaths (BARRY, 2008, p.260, grifos meus).

Era um momento histórico-social rico, no qual a morte ganhava espaço no imaginário público por meio de catástrofes e guerras retratadas diariamente na imprensa, assim como figuras célebres da sociedade e desconhecidos também tinham suas mortes, sobretudo as anedóticas, descritas com requintes de detalhes. Isso sem falar no espalhamento do ideário romântico via literatura: assim como as vidas exemplares, diz Barry, os imperativos comerciais do jornalismo logo abraçaram a figura do self-made man.

Assim, os obituários viriam preencher o vazio simbólico deixado pelos epitáfios, que já não davam conta da necessidade popular por narrativas de vida e morte mais complexas, cujo caráter romanesco, incentivado pelo aumento da leitura e pelo consumo cada vez mais difundido da imprensa, era demandado. Para tal, a análise de Barry aponta para a emergência de um tipo específico de narrativa: o da celebridade alcançável. Mesmo o nobre, ao ser digerido pela narrativa mortuária da imprensa, precisava ser traçado como um "superordinário" (2008, p.260), um ser com falhas e defeitos a ser superados. 
O obituário viria assim cumprir não só as funções de respeito e memória do epitáfio, mas também as de outros gêneros fincados na confluência entre biografia e necrografia: a legenda, a elegia, a eulogia - tipos textuais cujas funções, como "oferecer um modelo exemplar de vida bem vivida", "recordar o progresso e as conquistas de uma sociedade", ou retratar "as artes de bem morrer" (idem) já estavam estabelecidas antes do boom da imprensa. E viria também preencher anseios novos:

Death itselfcreated celebrities in the pages of early newspapers and magazines, as it still does today. At first this had a higher purpose, in presenting exemplary ways of dying, real-life examples of the ars moriendi that the Church and pious literature had promoted from medieval times. (...) Towards the end of the eighteenth century, however, more secular concerns emerged. (...) Death also became, in the burgeoning popular press, an occasion for scandal and entertainment, as the morbid preoccupation with spectacular or even comic fatalities in the pages of the early magazines demonstrate (BARRY, 2008, pp. 261262).

O obituário passa, assim, a cumprir uma função que não divide com outros gêneros: o de divertir o público por meio do caráter anedotário e romanesco, em narrativas genuínas de vida e morte advindas das classes médias e mesmo de figuras excêntricas dos estratos mais pobres. Em suma, o interesse do público pelo aspecto efêmero, cotidiano da vida das celebridades (na acepção mais ampla do conceito) se torna cada vez maior. A vida pessoal passa a dividir espaço com a profissional e a artística. A noção de fama, antes ligada a grandes feitos e fontes nobiliárquicas, as quais definiriam se o indivíduo teria trânsito no conjunto de ferramentas possíveis para construir um lugar na memória coletiva, passa por um alargamento, via imprensa:

In the eighteenth century, however, the new interest in the present moment and its transient wonders was also reflected in writing about death. The types of death literature increased and diversified, so that death became 'news' and people were celebrated for ephemeral talents and predilections, rather than exclusively for the lasting fruits of their mind or labor (2008, pp. 272-273, grifos meus).
Como esse "superordinário" se mescla ao extraordinário para transcender a realidade em um tipo de registro palpável e emocionante é uma conclusão apenas tangenciada por Barry. Faltou-lhe aprofundar o papel do caráter romanesco dessas narrativas, em justaposição ao caráter heroico, mítico, edificante dos gêneros anteriores. De início, poder-se-ia supor que o interesse do leitor por tais histórias fosse apenas mórbido. Mas o caráter romanesco parece ser a resposta de algo mais complexo: o obituário encontrou nos elementos das narrativas mortuárias e biográficas correntes material para originar um gênero único, depositário de sedimentações genéricas e funções sociais e estéticas diversas, das mencionadas elegias e eulogias religiosas ao laicismo puro dos folhetos e folhetins.

Afinal, a relação entre público e jornais nasce marcada por um esforço de fidelização. O caráter romanesco dos romances populares oferecidos aos nacos nos jornais atraía o público a outros textos com os mesmos elementos narrativos. É onde entrariam os obituários. O interesse por essa nova morte narrada amplifica-se justamente durante o período de emergência da imprensa.

Como sugere Hume (2000, p. 18), nos EUA, por exemplo, com a chegada da imprensa popular, "muitos jornais começaram a focar mais em notícias locais, incluindo a morte de cidadãos ordinários". Douglas (1978), ao analisar a emergência da "literatura de consolação" nos EUA dos anos 1830, chama atenção para o interesse local difundido por todo tipo de registro sobre a morte.

Quando os folhetins emergem como os textos mais lidos da história e a leitura de poucos registros canônicos (como a Bíblia) dá lugar a um número maior de leituras cada vez mais efêmeras, o obituário ganha espaço inalienável na imprensa de língua inglesa. Um espaço que, como se verá, cresce até hoje.

\section{Um estatuto em ascensão: mudanças no estilo, foco no leitor}

Pode-se ver o anseio em atrair um público interessado no caráter folhetinesco da narrativa mortuária, num momento de guerra de preços entre os jornais, na moda inaugurada pelo Guardian dos obituários ensanguentados. Mas os que almejavam o status de 
publicação séria utilizariam os obituários como "lugar nobre para veiculação de poder simbólico" (FOWLER, 2007, p. 45).

Para encontrar um equilíbrio entre o caráter romanesco das narrativas biográficas e essa espécie de respeito a interdições inerentes aos discursos sobre a morte; para agradar o maior número possível de leitores sem ferir a suscetibilidade de grupos ou indivíduos, os jornais acabaram conformando um gênero textual específico, que se equilibra entre o romanesco e o consolatório, entre o interesse narrativo dos elementos efêmeros da vida cotidiana e o caráter transcendental de que se revestem as narrativas sobre a morte.

O caso do diário The Independent ilustra bem o processo. Bytheway e Johnson (1996, p. 219), ao analisarem a emergência do status do obituário, "hoje reconhecido como um distinto gênero no jornalismo literário", indicam o ano de 1986, data do surgimento do diário, como um momento de virada na tradição dos obituários britânicos. Quando The Independent surgiu, já tinha uma coluna fixa de obituários e a intenção de utilizar o gênero (e uma nova elevação de sua forma narrativa, como se verá a seguir) para atrair leitores. Afinal, o obituário já era um gênero textual consolidado na imprensa de língua inglesa, presente na maioria dos periódicos. Assim, o obituário, filiado formal e tematicamente a gêneros estabelecidos, foi ganhando sua formatação atual. O mais surpreendente é como a imprensa conseguiu romper com uma ordem formalizada de lidar com a morte como homenagem (da qual o panegírico é o gênero definidor e a eulogia, seu improviso próximo) para instituir um novo regime discursivo, no qual a morte é utilizada como pontapé para narrar a vida de uma geração, iluminar a contemporaneidade com retratos biográficos sob configuração romanesca que flertam com o anedótico e humor, constituindo certa elegia contemporânea com objetivos comerciais.

Híbrido textual de convenções sobre vida e morte, o obituário sobreviveu como gênero ao ser capaz de servir como rito de passagem celebratório às famílias e prazerosa leitura a desconhecidos. Séculos depois de seu surgimento, o gênero segue em alta. Em uma época onde a imprensa escrita vive uma crise sem precedentes, um tipo de texto barato de produzir com alto índi- ce de aderência dos leitores, apoiado em uma tradição cristalizada em países de língua inglesa, é um trunfo inegável.

\section{Da estrutura narrativa à função social: o obituário no espaço biográfico}

Para melhor analisar a complexidade do fenômeno do obituário, decidi focar em um objeto literalmente mais palpável: as coletâneas. Há, hoje, dezenas delas no mercado, desde as editadas pelos próprios jornais a título de antologia (geralmente sob o título "book of obituaries"), às lançadas por profissionais não ligados a um periódico e àquelas que são simples compêndios temáticos. Os obituários vendem. As coletâneas proliferam.

A partir daí, a pergunta que se coloca é a seguinte: o que leva tanta gente a consumir um texto que nasce num contexto sociocultural específico (o pós-morte, muitas vezes exclusivamente privado), não só no espaço delimitado à sua emergência natural (a imprensa), mas em outras plataformas de leitura, como as coletâneas?

Uma primeira explicação para o interesse massivo pelos obituários, tanto no jornal quanto em volumes antológicos, aponta para a função social do gênero em uma cultura marcada pela representação da morte em narrativas biográficas. Nossa hipótese é que o obituário supre uma série de anseios em torno do lugar social da morte, ao passo que vai ao encontro do interesse específico (e crescente) por narrativas biográficas, a partir da imprensa e, logo além, dela.

Não à toa, o interesse pelo obituário sofreu um novo boom após a Segunda Guerra, segundo Starck (2004), na esteira da explosão maior da literatura de testemunho, no contexto da ampliação do que Arfuch (2010) chama de "espaço biográfico". Essa busca por narrativas do eu embebidas em valores de comunidade desembocaria em uma retomada ainda maior a partir dos anos 80 , justamente quando o fenômeno das coletâneas de obituários parece retomar parte dessa tradição, não apenas da biografia mortuária, mas do compêndio das mesmas, inscritas no tempo e pelo viés específico do fazer institucionalizado da imprensa. O que segue o movimento da guinada subjetiva e da retomada da importância do sujeito na narrativa 
das últimas décadas, no que Wievirorka (2002) chama de "era do testemunho".

Primordial para acessar esse imaginário social é o princípio teleológico organizador sugerido por Sarlo (2005): a síntese do passado, ordenado por suposições do presente, que impõe unidade sobre as descontinuidades, é central para um registro biográfico. E que evento pode servir de princípio organizador mais claro que o ponto final de uma existência que se pretende retratar? Que teleologia é mais eficaz que a trazida pelo conjunto de imperativos morais e tipologias narrativas nas representações de vida e morte? O obituário ocupa um papel primordial dentro das articulações do espaço biográfico - com o diferencial de lidar com outra fonte inesgotável de interesse humano, a morte - ou mais especificamente, uma estética da morte.

É o que diferencia o obituário de outros registros biográficos. A popularidade crescente do obituário passaria, assim, pela tradição de produção e consumo de narrativas de cunho pessoal que dominou a segunda metade do século XX, indo ao encontro da necessidade contemporânea de identificação subjetiva, de modelos sociais de realização pessoal, da curiosidade voyeur e da busca por aprendizagem com o viver do outro (ARFUCH, 2010). Ou seja, uma carência por identificação com figuras dotadas de caráter heroico que cristalizem na narrativa individual o sentido de um vazio coletivo explicaria o interesse por tais narrativas tanto em seu espaço original, a imprensa, quanto no espaço ulterior, decantando das coletâneas.

Para Dosse (2009), a leitura de registros biográficos (entre os quais pode-se facilmente inserir o obituário) fornece alívio de cunho existencial, ao permitir a comparação de modos de viver a vida (no sentido contido no termo bios, que origina lexicalmente o termo biografia). "Numa época em que a morte é assunto proibido, conforme bem percebeu o historiador das mentalidades Philippe Aries, a leitura de Vidas pode ser encarada como uma ars moriendi, um modo de familiarizar-se com a morte, de aceitá-la pondo-se no lugar daqueles que desapareceram" (idem, p. 18).

Dosse poderia estar definindo o obituário, esse texto que cria identificação imediata - comove, entristece e rejubila por meio de catarses e tons exemplares, além de iluminar as tintas de uma época, ecoar em sua história e diacronismo a evolução de uma cidade ou país. Como gênero formalmente instituído, segue à risca suas funções. É um registro que tem valor biográfico, repleto dessas "éticas de cotidianidade", para usar o vocabulário de Arfuch, tão presentes nessa espécie de apropriação da figura do herói, desse "acento coletivo" inerente à narrativa de vida que ganha mais poder com a morte do indivíduo ao adentrar o espaço biográfico.

\section{Análise textual: o obituário destrinchado}

Para entender a relação estabelecida acima entre o gênero textual, suas funções sociais, seu horizonte de expectativa e sua genealogia genérica, faz-se importante analisar detidamente ao menos alguns obituários. Far-se-á aqui, de forma detida, a análise de três textos, que cobrem um período longo e podem nos ajudar a comprovar o estabelecimento e a decantação do gênero.

O primeiro foi extraído da coletânea "Great Lives" (BRUNSKILL, 2007), que traz 124 obituários publicados pelo The Times entre 1916 e 2005. O obituário de Lord Kitchener, publicado em 1916, é o primeiro do volume, o mais antigo, o maior e um dos mais emblemáticos. A imagem que impera é a de um herói de guerra, impávido, sem medos, sem dúvidas. Kitchener é o ideal de homem militar, descrito por meio de suas ações calculadas com maestria ou tomadas de supetão do alto da coragem. Mas é um herói de poucas anedotas: sem humor, sem espírito, sem desejos além da vontade de servir à Coroa. Não é, em si, um personagem interessante em termos narrativos. Mas seu papel, no texto, é o de fornecer um esqueleto que permita o movimento da história das proezas militares do Reino Unido.

O texto é sumamente cronológico: traz a data de nascimento, o local, a filiação e a educação (no caso, a preparação para as artes da guerra na Royal Military Academy). Kitchener aplicou-se "incessantemente" e "vigorosamente" aos estudos de engenharia, e, em 1874, teve "sua primeira chance de aventura" (p. 1). A narrativa então toma as rédeas de uma trajetória teleologicamente orientada para o sucesso: na "Terra Santa", o jovem engenheiro mapeou territórios palestinos "com a perfeição a qual distinguiria os métodos de Kitchener 
na sua carreia futura" (idem) e enfrentou "perigo", "sofreu insolação" e foi "frequentemente atacado por bandos de ladrões", quase morrendo algumas vezes.

Dois elementos se entrelaçam na narrativa: os imutáveis, dados pelo destino (relacionados às virtudes do grande homem, universais) e os romanescos, historietas que conferem aventura e sabor temporal ao texto, ainda que marcadas pelo signo do heroísmo. No Egito, "sua personalidade e influência" ajudaram nas vitórias pontuais, o que rendeu medalhas. $\mathrm{Na}$ "reconquista do Sudão", cólera, tempestades de areia e mais de cem baixas aguardavam seu exército, enquanto Kitchener tinha a missão de construir uma linha de trem. "O destino o favoreceu” (p. 3) e ele achou água no deserto, "mas a construção da linha foi ainda assim o triunfo da imaginação" (idem).

A maioria do texto é composta pela descrição pormenorizada das campanhas militares encabeçadas por Kitchener, qual uma história oficialesca, monumental. Mas é uma história, também, romantizada. Em 1898, quando os trilhos alcançaram o Nilo, as tropas do comandante seguiram uma aventura narrada sob uma tessitura que não perderia em nada para um romance de cavalaria:

The sun was scorching and the marching hard, but the men were in fine condition and their spirit was superb. By September the plain of Kerreri was reached - the plain which, according to prophecy, was to be withered by skulls - and the cavalry now reported that the enemy was advancing (p.5).

A planície seria tomada pelo branco dos crânios inimigos. As tropas de Kitchener venceram o "sanguinário" califa, responsável pela "intolerável miséria de um regime que havia reduzido a população em sete milhões de almas" (p. 6). Aqui, além de reescrever a história monumental inglesa, o obituarista se dá o direito de preencher as lacunas históricas com elementos biográficos insondáveis: sentimentos, sensações, projeções que só poderiam ter sido tocadas por meio do relato de outras testemunhas ou do próprio biografado anos depois (o que mostra a força do relato pessoal para preencher as lacunas da história com ideologia, teleologia e hegemonia):
As Kitchener stood under the shade of the great tree on the river front to receive the congratulations of his officers, all the sternness had died out of him, for the aim of 14 long years of effort had been attained. He returned home to receive the honors and rewards which England does not stint to those who serve her well in war (idem).

É o enredo das narrativa que chama atenção. Como num filme de ação, onde o fim de uma aventura encerra o início de outra maior, o texto segue, avançando para a África do Sul: "Kitchener was not long left to enjoy his well-merited honours in peace" (idem). Há sempre uma tropa inimiga esperando (caso dos bôeres e suas milícias) ou, no caso da Índia, uma tarefa imperiosa a cumprir (reorganizar o exército britânico no subcontinente). $O$ texto não tem espaço para nada além da construção do personagem como herói. Sua personalidade só é descrita no contexto da tarefa militar.

O texto diz que a "organização era vista como o talento especial de Kitchener" (p. 13), mas tal afirmação é feita no contexto da indicação como secretário de guerra. $\mathrm{O}$ caráter de função nacional vence sempre: afinal, "ele praticamente não relaxava, a não ser que inspecionar as tropas pudesse ser descrito por esse nome" (p.14). Ele não tinha hobbies ou qualquer relacionamento afetivo. No último parágrafo, a seguinte frase resume sua vida sentimental: "He was not married" ( $\mathrm{p}$. 15). O obituário que abre a coletânea, assim, narra de fato a história de um século: um século de militarismo do império que pretendeu dominar o comércio mundial no século XIX.

Os textos de tal coletânea, sobretudo os mais antigos, são tidos aqui como parte de um subgênero específico, espécie de "elegia moderna" caudatária de uma forma laudatória e repleta de marcadores sociais de diferença ligados à hierarquia social. O subtítulo da coletânea (“A century in obituaries") já esclarece o intuito: retratar o espírito de um século por meio de homens selecionados. Uma relação metonímica se instaura: o conteúdo da coletânea, mais do que seus textos separadamente, deve retratar a história de uma era marcada por guerras (vide a ideologia nacionalista e imperialista) vencidas por "indivíduos excepcionais", por meio de cujas vidas seria possível restaurar a "história revela- 
dora, distintiva de tempos excepcionais nos quais eles viveram", como revela o prefácio (2005, p.xiii).

Um salto de oito décadas nos leva a um obituário publicado em 1997 no Guardian. Como se verá imediatamente, aqui, o único e o universal em cada indivíduo surgem não apenas da relação de fatos e eventos encadeada por um télos definido, mas é todo o tempo lembrado por adjetivos, advérbios, índices de admiração que transparecem a visão de um autor que paga tributo à memória de alguém. $\mathrm{O}$ horizonte de expectativa, porém, é outro em relação ao texto anterior: não o de uma nação grandiosa, de feitos militares, mas o da cultura de massa, do self-made man.

There was the unmistakable rangy figure and the forthright eyes, but you hear first in your head the immediately recognizable, most impersonated voice in the history of Hollywood - the languid yet adenoidal drawl. It was a woodwind instrument able to express a wider range of emotions than most film stars: there was his euphonious high tenor singing of Cole Porter's 'Easy to Love' in Born to Dance; the excitement as he feels a scream coming on in You Can't Take It With You; and the celebrated climatic filibuster from Mr. Smith Goes to Washington, when the voice becomes raw and husky without ever losing passion or conviction. More emblematically, James Stewart, who has died aged eighty-nine, was the voice of a certain kind of America. (...) As soon as America entered the Second World War, Stewart joined the Army Air Corps as a private, returning four years later a lieutenant colonel. He had flown twenty missions over Germany as a bomber pilot, winning the Air Medal and Distinguished Flying Cross. (...) Yet stars' real lives are far less real to audiences than those lived on screen, and Stewart's backing for the Vietnam War, Nixon and Reagan will be long forgotten while Jefferson Smith and George Bailey go on moving and entertaining us (OSBORNE, 2003, p.27).

O texto retrata um indivíduo particular, cuja vida é digna de ser retratada por seu caráter único - James Stewart tinha a voz mais conhecida de Hollywood - e, ao mesmo tempo, modelar, universal; assim, apresenta tal vida exemplar como um tipo representativo de uma época, uma geração, um país: era a "voz de certo tipo de América". Mas jamais perde a dimensão do detalhe que confere valor de verdade ao particular, exclusivo e único, aquele que viveu de verdade, de carne e osso, entre os contemporâneos que agora o leem. Uma dialética entre particular e universal, entre imanente e transcende se instaura, sob o signo de uma ética do cotidiano, como parte de uma reapropriação da noção fugidia de "vida boa" (RICOEUR, 2014, p. 186). Bem além do obituário do The Times, esse texto aproxima o leitor do personagem, operando, como diz Hume (2000), uma espécie de closure simbólico:

Publishing newspaper obituaries is one way modern humans deal with death and defend life, the obituary publication providing a sense of finality while celebrating the deceased's noteworthy attributes, preserving and legitimizing these important characteristics of Americans throughout the nation's history (p.20).

Ao longo do texto, o autor compõe o retrato de um tipo ideal que representa uma América de sonhos: ele estudou em Princeton, tornou-se ator, lutou por seu país na guerra, voltando para despontar em grandes papeis no cinema, acumulando medalhas de honra. $\mathrm{O}$ falecido surge em seu caráter de único e universal ao mesmo tempo: é um só e todos nós - é o que fez da vida (de importante e peculiar, suas decisões) e o que gostaríamos de ter feito no lugar dele.

A imagem de Stewart surge não como um endeusamento egotista, heroica num grau distanciado do real de quem lê, mas como ordem narrativa e orientação ética de costumes, sentimentos e práticas, fornecendo um sentido de finalidade à existência, não apenas do cidadão, mas da nação - de certa forma, ao encontro da definição de identidade narrativa de Ricoeur (2014, p.193), composta ao mesmo tempo pelo universal e pelo particular, o homem e o mito, via texto.

Por fim, chega-se a um obituário do primeiro volume das coletâneas do Daily Telegraph. Diferentemente 
dos casos anteriores, onde, ainda que em graus diferentes, o teor heroico, transcendental, exemplar se sobrepunha a qualquer leveza anedótica, ou mesmo a algum tipo de humor, esse texto faz parte de um movimento distinto, onde o obituário vem encontrar seu paroxismo literário. E digo isso não apenas por análise minha, mas cotejando paratextos que apontam nessa direção, tal intenção.

Como decantação aperfeiçoada de um gênero em movimento, tal texto faz parte de um momento histórico-social específico: a nova leva de obituários produzida dentro de uma formatação deliberadamente diferente pelo Daily Telegraph a partir de 1986, quando a seção fica a cargo do eminente jornalista Hugh Massingberd. O prefácio da coletânea, assinado pelo mesmo, faz um esforço nesse sentido, de demarcar historicamente o momento em que os obituários passaram a ser uma questão importante para lançar uma vanguarda no jornal, para competir com o já estabelecido The Times. Foi ao se deparar com a coletânea "Brief Lives", do século XVII, nos anos 1960, que ele se viu determinado a se dedicar à "crônica do que as pessoas realmente gostam, por meio de anedota descrição e desenho de caractere, em vez de apenas destrinchar o currículo (MASSINGBERD, 1996, p. vi, tradução minha).

O que sobressai desse paratexto é, sobretudo, como a depuração do gênero, alcançada com a proposta de retomar uma tradição de crônica biográfica mortuária do século XVII, baseia-se na acumulação genérica, de seleção de elementos de gêneros que narraram tópicos de vida e morte ao longo da história, até encontrar uma formulação do gênero equilibrada, em termos tópicos e narrativos, entre moralismo/virtude, entre o monumentalismo histórico e o caráter anedótico/fabular. Depuração que iria ao encontro das demandas contemporâneas por narrativas de vida exemplares, mas não inocentes, inspiradoras, mas não moralistas, sedutoras, mas calcadas na história real. É o equilíbrio desses elementos que fará a unicidade do que chamo de obituário "contemporâneo". E o melhor exemplo dessa categoria são os obituários do Daily Telegraph. Para demonstrar como a publicação criou uma formatação genérica ímpar, cujo estilo reflete uma identidade única entre o gênero e o jornal nascente, escolhi o primeiro volume das coletâneas publicadas pelo periódico a partir de 1995. Pelas semelhanças e diferenças no estilo dos textos, creio ser possível demonstrar a unicidade do gênero de obituários alcançado pelo Daily Telegraph.

Afinal, o que faz uma vida "excêntrica", como define o subtítulo da coletânea? O termo tem relação com a proposta de não apenas colaborar com a hagiografia de figuras notáveis na sociedade, mas garimpar histórias e personagens ilustrativos de uma época. E deixa claro que o objetivo do obituário de figuras desconhecidas, que entram para um panteão especial da memória nacional, é mostrar como vidas inesperadas podem servir de leitura agradável e enriquecedora ao leitor de jornal.

O primeiro obituário do volume é ilustrativo da definição acima. Seguindo uma fórmula encontrada na maioria dos exemplos da coletânea, o texto começa com nome, registro da morte e idade, seguido por uma sentença definidora do status do personagem: "was the eccentric artist on whom the novelist Joyce Cary based the character Gulley Jimson in The Horse's Mouth" (p.1). Eis que surge, em uma só frase, o retrato biográfico do "personagem", imagem que será passo-a-passo confirmada pelo movimento do texto. Enquadrado sob o ponto de vista do anti-herói, do excêntrico que faz tudo errado, mas vence no fim por ter carisma, talento e sorte, o texto apela nitidamente a um estereótipo, o "artista louco". A tópica é didaticamente introduzida, preparando o terreno para uma narrativa tradicional: como um indivíduo "excêntrico" dribla as peripécias da vida a seu modo, produzindo humor.

Mas a chave de leitura (referencial, no caso) oferece um ponto de vista que não é moralista, e sim anedótico. $\mathrm{O}$ artista louco é também o anti-herói, a figura curiosa blindada do linchamento por sua excentricidade sobrenatural. Assim, a história que veremos não é monumental ou virtuosa, mas sobretudo anedótica. Mas é uma vida que o gênero narra, com começo, meio e fim, o que demanda uma noção de trajetória (um télos), um percurso ladeado por feitos. No caso de Wilde, há feitos e "anti-feitos": a forma inesperada com que seu caráter (sua personalidade, na definição plutárquica) reage diante das provações da vida é que dá sua dimensão romanesca.

Como uma figura quixotesca, o excêntrico pintor segue sua rota. De início sabemos que é uma pes- 
soa literal e literariamente imitável, tanto que serviu de exemplo para um outro sujeito, ficcional. Segundo o texto, sua trajetória foi emulada pela arte do escritor (na literatura, Jimson é um artista falido e desiludido que ganha a vida enganando seus amigos ou mesmo vivendo de seus favores.) $\mathrm{O}$ adjetivo excêntrico dá conta de explicar muito com pouco espaço. Usado junto da referência literária, dá o tom do texto: uma anedota engraçada sobre uma figura peculiar.

Ao narrar a engraçada história de que todos confundiram a morte de um vizinho com a sua e publicaram um obituário seu por engano, seguido de outros fatos únicos (como o fato de o pintor ter perdido a vista de um olho na infância), o autor dá espaço para elementos romanescos que, quais fait divers quaisquer da imprensa ou mesmo de uma fábula, colaboram para construir uma imagem única e acessível ao mesmo tempo. Afinal quantas pessoas têm acesso ao próprio obituário publicado enquanto vivas? Uma anedota viva surge no texto. Mas não só isso.

No quarto parágrafo, o autor mostra como essa figura e seu trabalho foram esquecidos por décadas - tal situação encerra um efeito patêmico singular: impede que a figura seja execrada pela imaginação do leitor, concede-lhe humanidade. Wilde é retratado como alguém que fazia tudo errado e por isso era adorado por alguns. "An inability to organize himself professionaly": presume-se que a norma social dita que o indivíduo seja autossuficiente profissionalmente. Mas aqui, não compartilhar desses valores faz do personagem o que ele é: o anti-herói. Mesmo pobre, ele dava seus quadros para os amigos, o que dificultava sua relação com as galerias.

Se a narração começara, como é praxe em perfis contemporâneos, in media res, o fio cronológico da biografia é retomado no sétimo parágrafo, quando se diz que ele nasceu em 1905 e só foi estudar artes aos 21 anos, quando os amigos dos pais os convenceram a deixá-lo seguir seu rumo natural. Aqui, a ideia de que há uma predestinação para cada indivíduo floresce. No parágrafo oito, o texto diz que suas primeiras pinturas pouco diziam do que seriam "the extremes of expressionism which characterized much of his later work". O nono parágrafo assume de vez o tom irônico e avança sobre o território da ficcionalidade, ao postular a noção narrativa onisciente sobre seus sentimentos e razões para tomar decisões na vida:

There have been periods of inactivity such as wartime in the Pioneer Corps or when he felt he had painted himself out. But his premature obituary seems to have stimulated him, for after establishing his identity with the local police, he felt he was in some way resurrected and being given a second chance (p. 2).

O autor não releva como acessou os sentimentos (he felt) do obituariado: não deixa claro se ouviu de parentes e amigos, se leu confissões ou se esse é apenas um artifício narrativo para conceder uma dimensão psicológica ao defunto. Em dois momentos usa o verbo sentir: quando Wilde sentia que havia esgotado suas capacidades como pintor e quando, após o "obituário prematuro" (e aqui uma relação intertextual curiosa é estabelecida, na medida em que a vida do obituário, sugere-se, mudou justamente após o caso do obituário falso, agora recontado pelo verdadeiro), Wilde "se sentiu renascido e tendo ganhado uma segunda chance". De quem? O destino parece assumir as rédeas de uma vida predeterminada - via narrativa.

É como se, como diz Ricoeur, somente o tempo narrativo pudesse organizar o tempo da experiência humana. No texto, após os acontecimentos elencados, "his paintings took on a powerful vision." Visão, aqui, pode ser entendida como imagem, representação, ou visão do futuro, antecipação apocalíptica, o que indica o humor quase ácido do texto. E, segue o texto, após tais acontecimentos, ele retoma o caminho predeterminado. Sua vida e obra são tratadas na TV. Uma retrospectiva acontece. Anos depois, ele exibe sua obra nos EUA. Ou seja, ele ganhou a dimensão que merecia. O advérbio "finalmente" desmascara a engenharia narrativa empregada.

Um acontecimento fundamental encerra a narrativa com a imagem intencionada: em 1972, um filósofo rico levou Wilde para morar com ele. Após sua morte, Wilde ficou morando na casa, "in what he called his 'graveyard', a stable with no mains water or drainage". Aqui fica selada a excentricidade do personagem. Mesmo tendo adquirido fama e dinheiro, Wilde preferiu viver 
o fim da vida numa tumba: um templo para excêntricos. Ele não era um pobre coitado. "He lived on welfare and spent most of his money on drink." Ele apenas fazia escolhas peculiares. A excentricidade é a chave para explicar os acontecimentos de sua vida, para ligá-los em uma narrativa coesa: a trajetória de ascensão e queda de um esquisitão.

O que fica claro a partir da análise dos obituários é o papel do biográfico na constituição de um sujeito que vira personagem, cuja vida é narrada em retrospectiva, por meio de um enredo de cunho ficcional, teleológico, mitologizante e em consonância com as expectativas de seu público leitor. Cada texto cria uma imagem biográfica, o retrato de uma vida, por meio de um enquadramento que emerge, retoricamente, a partir dos paratextos, das frases introdutórias, do movimento do texto, do tom, da imagem (ou, poder-se-ia dizer, pensando nos santos de Jolles, da figura). Tal imagem permite a identificação imediata do leitor e a classificação segundo o arcabouço da memória coletiva em sua relação de referência: o real objetificado, apesar da mitologização teleologizante da narrativa.

O que vai ao encontro do que Sarlo chama de interesse romanesco: "O passado volta como quadro de costumes em que se valorizam os detalhes, as originalidades" (2005, p. 17). Os exemplos acima mostram como tal narrativa como gênero consegue articular detalhes repletos de efeito de real e traços de memória, amarrados sob uma narrativa que enquadra a figura que surge como personagem de uma história dotada de valores universais. Tal urdidura permite que uma vida singular se inscreva no regime da memória nacional, sem perder o sabor de uma existência real.

Para tal, usam-se tópicas que alimentam a narrativa de vida: temas ligados à consolação, ao futuro, ao passado, à construção do biográfico; a pobreza na infância, o sucesso profissional, a contribuição para a sociedade, os hobbies que humanizam uma vida dedicada ao trabalho e à família, a relação com Deus, com os subalternos; os universos do herói, do familiar, do grupo, do nacional, a guerra, o amor. Como uma caixa de fer- ramentas tópicas, tais registros conseguem construir a engrenagem de uma narrativa exemplar, mas que não peque pelo caráter consolatório - é o romanesco que confere o prazer da leitura: historietas sem importância (narrativa) que dão humanidade, funcionam como índice de realidade, apoiam o valor da narrativa no biográfico, no que foi, de fato vivido.

Enquanto isso, a morte confere o caráter transcendental, via referências ao falecimento, à doença, aos sobreviventes. E o télos, dado de partida, orienta a estrutura da história, enquadrada por meio de arquétipos, tipos identificáveis cujas trajetórias em vida se moldam por tais télos verossímeis, sobretudo posto que repletos de sentido moral. São imagens, retratos que permitem a identificação imediata do leitor e a classificação segundo o arcabouço da memória coletiva, formada por esses "pontos de contato" que cria uma base comum, como pensa Halbwachs (2006, p. 12).

O exemplo permite ainda vislumbrar uma reflexão mais profunda sobre o interesse do público sobre os obituários: a confluência entre biografia e morte sob o prisma da fruição instantânea. Biografia sobre um morto recente, muitas vezes um cadáver cujo corpo "mal esfriou", no dizer popular, cuja narrativa está disponível no jornal diariamente, na seção fixa, a despeito da ausência de catástrofes ou outros golpes do destino, o obituário é de fácil acesso e leitura agradável: é um snapshot condicionado pelo télos de uma narrativa exemplar.

Em um artigo sobre a importância das narrativas biográficas curtas, Walter (2006) afirma que a discussão acadêmica tem esquecido "a diferença genérica entre biografias em escala completa e as 'vidas breves"' (p 330). Focando-se nas biografias curtas de Strachey, Walter diz que o autor, "ao tratar seus sujeitos como exemplares, e usando seus ensaios não para celebrar os indivíduos, mas para identificar questões maiores referentes a temas sociais e culturais", retomava uma tradição que viria desde Plutarco. Aí estaria a magia do que ele chama de "disciplina da brevidade": "ao sacrificar a amplitude do livro, é preciso se concentrar imediatamente no que se quer dizer, e por que importa dizê-lo de qualquer forma” (idem): 


\begin{abstract}
It also shapes the most common forms of short lives we now encounter: obituaries and entries in national dictionaries of biography. Granted, the most mundane of these provide no more than a record, but the best are informed by a strong sense of why "this" life mattered, usually conveyed along with a feel for the larger social and cultural context. The discipline of brevity, the question of why a particular life deserves consideration, brings a lucid argument to the fore (idem, grifos meus).
\end{abstract}

É quando chegamos a um ponto nevrálgico em relação ao sucesso dos obituários no espaço biográfico. Além da questão da «imediaticidade» (o acesso ao biográfico é quase instantâneo em tempos de internet), tais textos se aproveitam de seu tamanho reduzido para seduzir leitores sem tempo ou sem costume de leituras extensas, que não se aventurariam em volumes biográficos de mil páginas para compreender e saborear a trajetória de um indivíduo. A vida breve, diz Walter, "não é apenas ilustrativa, mas também a melhor maneira de entender algumas facetas inexploradas de instituições, da sociedade ou da história" (p. 333).

Para Susan Stewart (apud CODELL, p. 109), o formato reduzido dessas biografias remeteria a "versões nostálgicas da infância e da história" (idem), ou seja, uma diminutiva, e por isso, manipulável, versão da experiência. E o tamanho do texto permitiria outro tipo de intimidade, não apenas físico, espacial, mas cultural, com base na capacidade de o leitor de absorver o conteúdo e utilizá-lo externamente como aforismo, provérbio, epigrama - caráter didático que permitiria que a "vida" servisse como mostra de conhecimento (ainda que rápido) sobre a cultura e da sociedade.

O obituário permite ainda uma fruição facilitada pelas delimitações do gênero. O espaço delimitado da imprensa (a seção de obituários) e o gênero fixo que a preenche permitem um consumo de ordem iterativa. A coluna se encontra todos os dias na mesma página dos mesmos periódicos, à disposição para consumo imediato de um tipo de narrativa genericamente coerente, tanto do ponto de vista temático como remático, satisfazendo o que Eco (1993) classifica como um desejo de voltar a encontrar um esquema. Os personagens são diferentes, mas, ao mesmo tempo, sempre os mesmos. Os tópicos que orientam a narrativa são frequentes; os enquadramentos teleológicos, idem; o "tipo" heroico remete a alguém que completou bem a tarefa inerente à vida ou foi atraiçoado pela morte no decorrer dessa busca.

O leitor busca assim saciar uma "fome de redundância" por meio da iteração de "tópicos fixos e recorrentes". Ele sabe o tipo de história que vai encontrar: ela é previsível, encerrada dentro dos limites mitológicos do herói contemporâneo ocidental - mas apresentada de forma romanesca, como uma vida que se desenrola e traz surpresas, sem, porém, arranhar o télos da narrativa, que, em última instância, congraça o personagem à categoria de herói.

\section{As coletâneas: um espaço fixo para uma narra- tiva efêmera}

Até aqui vimos que o obituário é lido como texto verdadeiro atrelado ao discurso real de uma vida e uma morte atestáveis pelo discurso da imprensa, ainda que sob o prisma de uma narrativa imaginativamente rica, eficiente, posto que breve, acessível, de consumo iterativo, facilitada pela formatação do gênero, textual e espacial (que vai ao encontro de um horizonte de expectativas bem delimitado). Sobretudo, sua leitura passa por ter, nessa formatação, em seu caráter textual, uma urdidura teleologicamente orientada que promove a emergência de uma figura particular e exemplar ao mesmo tempo, cujo efeito patêmico aproxima-se do mito, ou mesmo da elegia, mas sem perder a aura dos discursos sob um regime de verdade.

Dessa forma, se o leitor consome o obituário não apenas para se informar da morte ou ritualizar seu luto, mas como pura fruição estética de tópicas e estilos discursivos, não seria uma questão de investigar seu valor literário? A despeito da pejorativa herança do termo, não seria uma questão de valorização estética e de fruição (de uma) poética o que está em jogo?

Afinal, a literatura é um "heterogêneo", sugere Costa Lima (2006), tão múltiplo que abarca em seu universo conceitual qualquer gênero que para ele acabe convergindo: há sempre a possibilidade de um registro textual "mudar sua inscrição originária" (p. 348) e ganhar nova relação de leitura prova-o. Pois é o potencial 
de sensibilização estética do texto o que garante seu estatuto literário, independente da ficcionalidade de origem (ou sua intencionalidade ficcional). Esse "correlato sensível" que dá vida específica ao texto depende de certa "suplementaridade literária" (p. 352), relacionada a uma possibilidade de "dupla inscrição discursiva". Não haveria um "deslocamento", mas uma "sincronia": a marca da primeira inscrição não desaparece, mas jaz ao lado da segunda: a valoração estética do texto como leitura sensível.

Quando nos perguntamos acima por que leitores contemporâneos consomem obituários, não só nos jornais, mas nas coletâneas, concluímos que eles lhes conferem uma sobrevida estética que é o corolário do que disse até aqui. A coletânea não só prova o interesse do leitor por tais narrativas mortuárias de caráter biográfico esteticamente refinadas, como explicita a valoração literária (em uma segunda inscrição, de cunho puramente estético) desse tipo de texto em detrimento de seus correlatos na imprensa (ou seja, o restante do jornal, das reportagens strictu sensu).

Vejamos alguns elementos desse tipo de publicação em outros exemplos. "Portraits of Grief”, coletânea de obituários dos mortos no atentado de 11 de setembro nos EUA, por exemplo, trazia os perfis em ordem alfabética, prontos para consumo. Tanto no volume impresso quanto na versão na internet, cada história vinha acompanhada de um nome e um título que define o tema (como "The captain of the ship"). Em outra coletânea (OSBORNE, 2003), o sumário elenca os textos por categorias: artistas, esportistas, "movers, makers and doers", como se fossem produtos em uma prateleira - é assim, tipificados, figurados, que tais perfis migram da efemeridade do jornal para a duração das coletâneas.

Tais "paratextos", na acepção de Genette (1991), garantem a fruição do texto, organizam sua leitura, condicionam a percepção genérica e terminam por formatar a experiência estética das narrativas, como snapshots da morte para a vida. Anos depois, ao reler o perfil na coletânea guardada na biblioteca, o leitor encontrará os perfilados analisados acima à disposição para preencher outros tipos de vazios constitutivos. Os prefácios não ficam atrás no sentido de condicionar a fruição dos perfis como algo extraordinário.
Tal poder de sedução pode ser ainda maior quando a atenção estética se deve a uma condicionalidade. Partindo da noção kantiana de valor estético como satisfação desinteressada, Genette (1991, p. 71) afirma que o valor literário (interesse de leitura esteticamente orientado) é condicionado nesses casos por uma questão de ordem afetiva. Seria o caso de um regime de avaliação do texto (literário) não constitutivo, mas condicional, o que abarcaria todo texto cuja literariedade subsiste no que agrada ao leitor. Assim, é o caráter afetivo o que institui a "atenção estética": um poder de sedução, ainda maior quando se deve a uma condicionalidade, à sedução involuntária encontrada num texto não-ficcional em prosa - caso do obituário.

Não queremos aqui definir o que é literatura. Mas partimos desse gasto debate para concluir que o obituário está longe de ser apenas um gênero jornalístico, um tipo de registro restrito ao universo epistemológico da imprensa. Se milhões leem o obituário de um desconhecido é por apreciar esteticamente uma narrativa e não para se "informar", stricto sensu, da morte de uma pessoa. Além disso, o próprio espaço destinado ao obituário no jornal não se reduz à "factualidade". E se outros, não satisfeitos em lê-los nessa mídia, compram coletâneas que não guardam relação espaço-temporal com o jornal, é pelo "aspecto" de tais textos, na concepção genettiana - pelo caráter extemporaneamente "estético" do obituário. Não é somente o conteúdo do relato por si mesmo, mas precisamente as estratégias (ficcionais) de representação, sua construção narrativa, o vaivém da vivência ou da lembrança, fixadas em um registro dotado de autenticidade, o que atrai os leitores.

Daí concluir-se, com base nos autores citados e na análise dos textos das coletâneas, que duas questões são centrais para entender o interesse do leitor pelos obituários. Primeiro, os obituários aqui analisados são narrativas do eu que permitem identificação subjetiva e, ao mesmo tempo, transcendência da natureza ordinária do cotidiano, o que vai ao encontro da carência contemporânea por identificação com o outro (ARFUCH, 2010, p. 15) e pela busca por figuras heroicas que cristalizem na narrativa individual o sentido de um vazio coletivo - o que explica o interesse por tais narrativas biográficas tanto em seu espaço original, a 
imprensa, quanto em seu espaço ulterior, decantando: as coletâneas. Segundo, são perfis burilados pelo ofício de escritores de jornal, adaptadas ao estilo de narrativa que foca nos detalhes pungentes e na organização do texto pelo télos da narrativa exemplar, em respeito à ética do luto e aos regimes de verdade das representações da morte e da imprensa como instituição.

Em última instância, tais registros, que apreendem a nota fulgurante da vivência (idem) cristalizada após a morte e por isso se tornam capazes de iluminar o instante e a totalidade, o individual e o coletivo, e, em última instância, o universal e o transcendental, encerram uma poética específica, que encontra na fruição estética da leitura o fechamento de um ciclo. O que acende nesse tipo de texto um interesse genuinamente "literário", de tipo comprovadamente genérico.

Ao tratar tais registros como parte de um gênero, busca-se compreender sua existência como relacionada a uma "tradição formal particular". Por isso faz-como sugere Jolles (1976, p. 30): trabalha-se o obituário como "um tipo acabado de realização particular", o que permite a vantagem de analisar as relações envolvidas na culminação do gênero como resposta a demandas sociais. Uma "economia da expressão" que vai ao encontro do que Arfuch classifica como articulação da proeminência do vivencial com a obsessão de certificação. É "esse suplemento de sentido que se espera de toda inscrição narrativa de uma 'vida real", e que "remete a outro regime de verdade, a outro horizonte de expectativa" (p. 59).

No caso do obituário, narrativa jornalística, a ficcionalidade é inerente ao modo de narrar. Sua estrutura bebe na elegia, na legenda, na eulogia, no epitáfio, assim como em formatos contemporâneos - o perfil jornalístico, a notícia, os fait divers. O obituarista, por sua vez, investido da função a ele outorgada pela instituição (imprensa) e pela sociedade, seu grupo de leitores imaginados e seus horizontes de experiência, "codifica" eventos diversos da vida de um indivíduo em função da estrutura de enredo cristalizada pelo gênero, pelo conjunto de convenções que, por sua vez, condicionam a busca pelos elementos históricos, fatos biográficos.

Suspenso (abduzido), o obituariado é levado para o mundo do texto, onde, conjurado pelas crenças pes- soais do escritor e pelas normas institucionais e demandas sociais ligadas ao gênero, será transformado no protagonista de uma história, verossímil e, no limite filosófico aceitável, verídica. Por isso se encontra nos obituários mais criativos essa espécie de "desdobramento interior à ficção" (VOGEL, 2008) que garante uma "vitalidade cultural" a outros textos da imprensa, como crônicas e o que se convencionou chamar, no Brasil, de "grande-reportagem".

Como essas, os obituários são histórias (muitas vezes bem) narradas, calcadas em tópicas enraizadas em narrativas míticas, facilmente atualizáveis e logo, imperecíveis. Vogel analisa tal potência que extravasa o espaço da notícia para projetar-se em um mundo duradouro nos fait divers.

Embora a atualidade seja uma das razões da existência do jornalismo, esse presente imediato ganha uma potência, um devir, à medida em que os textos publicados operam como sintomas de época. Alguns textos associados ao jornalismo, e o fait divers situase entre eles, ganham, por isso, outra sorte de durabilidade, porque se inscrevem na ordem da memória. (2008, p. 140)

O obituário, longe de se restringir a um fait divers, compartilha a mesma inscrição na ordem da memória: sobrevive ao imediatismo do jornal para ganhar os volumes das coletâneas. Ao revestir o ordinário de uma vida com uma capa de simbolismo, de dimensão metafórica, pelo uso de tópicas tradicionais e de uma urdidura de enredo reconhecível, o obituário ganha um estatuto único, no encontro do anedótico com o exemplar-universal, do mítico com o referencial, do cotidiano com o sublime. Povoada por esses personagens e fatos em forma de lugares-comuns discursivos, topois narrados de forma a conjugar o universal e o peculiar, o anedótico e exemplar, a narrativa ganha vida além do discurso jornalístico.

Assim, adentra terreno epistemologicamente incerto. Sigo o raciocínio de Rancière (2005), para quem vivemos uma era de fronteiras irreconhecíveis no âmbito do discurso e da cultura. É nesse "regime estético das artes" (2005, p. 47) que o autor encerra todo objeto 
depositário de alguma atribuição de uma beleza e que assim partilham de um regime específico do sensível, alterando-o por meio de uma "potência heterogênea" (p. 32). O que, para Vogel, explica por que determinados produtos do jornalismo navegam em dois mundos, o da produção noticiosa (e seu consumo) e o de certa fruição de cunho meramente estético.

Por compartilharem traços que são atribuídos às artes (finalidade comunicativa que transcende o imediato e que, retirada do contexto pragmático, se estrutura de modo autônomo), esses textos operam simultaneamente como complemento e como desvio, na ficção social que a mídia torna dominante (idem).

Como na tradição romântica, que via na literatura um manancial de experiências virtuais por meio das quais o leitor sai fortalecido, deixando o ordinário da vida privada para acessar o universal - parte desse "laboratório do juízo moral" que Ricoeur (2014, p. 145) vê na narrativa e de onde o leitor, ao reconfigurar em seu mundo, extrairia também uma "narrativivização do caráter" (p. 169) -, pode-se ver na seção de obituários de jornal - e, mais ainda, no almanaque de vidas breves que é a coletânea - uma forma de acesso formal, rápido e estável, a narrativas de vida e de morte: uma espécie de biográfico fast food.

Essas pequenas biografias, urdidas segundo estruturas ficcionais (ainda que o estatuto não perca sua relação certificatória com o discurso da imprensa), são lidas por motivos que vão do rito fúnebre escandido por estímulos do presente ao esforço de memória coletiva, sem abandonar o simples prazer da leitura, seu apelo estético. Cumprem, assim, a tríade poíesis-aísthesis-kátharsis que Ricoeur (2012, tomo 3, p. 306) crê inerente a qualquer literatura. No caso, uma literatura de jornal, dele oriunda, mas que mantém a especificidade de sua poética, e, assim, o apelo estético do gênero, mesmo quando abandona seu caráter efêmero em prol da estabilidade do volume - quando ganharia sua dimensão ético-estética derradeira: a do catálogo. A coletânea pode ser vista, assim, como um catálogo de vidas breves sempre à mão.

\section{Notas}

1. Obituários poderiam ser definidos como anúncios mortuários acompanhados de biografia publicados em periódicos da imprensa. $\mathrm{O}$ tipo de texto que se analisa aqui e que ganhará o corpo das coletâneas estudadas, porém, é um gênero cristalizado ao menos desde o fim do século XIX, que abarca uma narrativa biográfica pós-morte escrita por jornalistas e publicada na imprensa, geralmente de língua inglesa, com estilo mais ou menos sofisticado e tópoi delimitados segundo o extrato que os consome.

2. Em VIEIRA (2014), procuramos delimitar o papel do obituário como gênero textual específico. A noção de gênero da qual partimos o vê como classificação pragmática e social de textos, interessada "no modo como o discurso funciona como uma prática modelando os significados de um ambiente social" (FROW, 2007, p. 1630). O conceito é entendido empiricamente, do ponto de vista da recepção: ele viria da acumulação de usos, da sedimentação e migração de outros gêneros, ligado a um horizonte de expectativas que se torna real quando há textos que o exemplifiquem. Analisar a emergência e a manutenção do obituário como gênero é essencial para compreender seu lugar social, ontem e hoje.

3. As primeiras notas de falecimento surgem em 1785, e os primeiros obituários, em 1835.

4. E não apenas no Reino Unido. Em 1704, o americano Boston News-Letter publicava uma seção de obituários. Em 1851, quando foi lançado o New-York Daily Times, que daria origem ao New York Times, já havia a coluna (STARCK, 2004, p. 56).

5. "Fama e morte encontram uma nova relação nesse período, tendo a grande expansão do jornalismo popular impresso no fim do século XVIII trazido consigo a possibilidade de que praticamente qualquer um encontrasse uma forma de imortalidade secular, impressa ou em imagens. O outro lado da moeda é que as fracas leis acerca dos libelos também permitiram à imprensa favorecer o interesse de seus leitores pela vida privada de figuras proeminentes, até após sua morte (tradução minha).

6. Como fica claro em VIEIRA (2014, pp. 24-33), antes do estabelecimento da imprensa como principal veículo de circulação de imagens de pessoas públicas, a prática de retratar os mortos pelo que viveram não poderia estar dissociada de tradições formais estabelecidas, cujas regras sobre como se reportar aos mortos encontravam acolhida na literatura e nas artes visuais, incluídas as trabalhadas sobre a rocha, as tumbas. Epitáfios, legendas, elegias, eulogias e panegíricos, gêneros escritos, visuais e orais ao longo da história, antecedem o obituário como possibilidade 
de representação da vida a partir do momento da morte. "Pode-se inferir assim que a conformação atual do gênero obituário não só efetuou uma série de empréstimos valiosos a gêneros de vida e morte predecessores, em termos de conteúdo e forma, de tópica e estilo narrativo, como adaptou e mesmo resignificou alguns de seus elementos para lidar com a demanda social específica de um público" (idem, p. 33), que agora encontrava nesse novo espaço de negociação simbólica, a imprensa, seu locus ideal.

7. "A morte em si mesma criava celebridades nas páginas dos primeiros jornais e revistas, como o faz ainda hoje. De início, o propósito era superior, de forma a apresentar formas exemplares de morrer, exemplos reais de certa ars moriendi que a Igreja e a literatura pia já promoviam desde tempos medievais. (...) Por volta do fim do século XVIII, porém, preocupações mais seculares emergiam. (...) A morte tornou-se também, na imprensa popular burguesa, uma ocasião para o escândalo e para o entretenimento, como a preocupação mórbida com fatalidades espetaculares ou mesmo cômicas nas páginas das primeiras revistas demonstra" (tradução minha).

8. "No século XVIII, porém o novo interesse no momento presente e em surpresas passageiras também se refletiu na literatura sobre a morte. Os tipos de literatura mortuária cresceram e se diversificaram, de forma que a morte se tornou 'notícia' e pessoas passaram a ser celebradas por talentos efêmeros e predileções, e não só pelos frutos duradouros de suas mentes ou de seu trabalho (grifos e tradução meus).

9. Tal literatura tinha espaço tanto em manuais de luto quanto biografias de figuras destacadas, sobretudo pastores, crianças e mulheres. A relação com o arcabouço religioso é nítida. São os pastores e as mulheres devotas os autores, seus personagens e seus consumidores. Uma relação entre religião (presbiteriana) e a escrita da morte se desenha, assim, como uma das explicações para a emergência do obituário contemporâneo e sua disseminação no mundo de língua inglesa e cultura anglo-saxã.

10. Vide a pesquisa de Ljung (2000).

11.É o caso do The New York Times, do The Guardian (ambos mantém edições anuais), do The Daily Telegraph (que têm ao menos cinco volumes), do The Times, da Economist e do Washington Post. Há ainda coletâneas com textos de jornais menores e outras voltadas a temas específicos.

12. É o que se verá, mais à frente, com a análise do prefácio e do obituário do The Daily Telegraph.

13. O espaço de um artigo não permitiria a análise do texto de muitos obituários. Tal empreitada é realizada em Vieira (2014, pp. 129-166).
14. O sol estava escaldante e a marcha, lenta, mas os homens estavam em plenas condições e seu moral era elevado. Até setembro, a planície Kerreri foi alcançada - planície que, segundo a profecia, deveria ser coberta por crânios - e a cavalaria agora reportava que o inimigo avançava (tradução minha).

15. Enquanto Kitchener, à sombra da grande árvore à beira do rio, recebia as congratulações de seus oficiais, toda a austeridade o havia deixado, já que 14 anos de esforços haviam sido bem-sucedidos. Ele voltou ao escritório para receber as honras e recompensas que a Inglaterra jamais nega àqueles que a servem bem na guerra (tradução minha).

16. "Havia a inconfundível silhueta esguia e os olhos francos, mas o que chegava antes à mente era aquela voz imediatamente reconhecível, a mais imitada da história de Hollywood - aquela pachorra lânguida, meio fanha. Foi um instrumento de sopro capaz de expressar um espectro mais amplo de emoções do que a maioria das estrelas de cinema: havia sua versão melodiosa, em tenor alto, de Cole Porter cantando 'Easy to Love' em Born to Dance; a animação de quando ele sente um grito surgindo em You Can't Take It With You; e o celebrado pirata de Mr. Smith Goes to Washington, quando sua voz se torna crua e rouca sem jamais perder a paixão e a conviç̧ão. De forma ainda mais emblemática, James Stewart, que morreu aos oitenta e nove anos, era a voz de um certo tipo de América (...) Assim que o país entrou na Segunda Guerra Mundial, Stewart se juntou à Aeronáutica como soldado raso, retornando quatro anos depois como tenente-coronel. Ele havia sobrevoado a Alemanha em vinte missões como piloto de bombardeiro, ganhando a medalha Air Medal and Distinguished Flying Cross. (...) Ainda assim, a vida real das estrelas é bem menos real para o público do que aquela vivida na tela, e o apoio de Stewart à Guerra do Vietnã, a Nixon e a Reagan terão logo sido esquecidos, enquanto Jefferson Smith e George Bailey seguirem nos entretendo" (tradução minha).

17. Interessante notar na presença de detalhes biográficos, insignificantes do ponto de vista funcional da narrativa, o "efeito de real" postulado por Barthes (2004, p. 184). O prestígio do "aconteceu" faz parte da contemporaneidade: há um gosto de nossa civilização por produtos culturais marcados pela lógica do documento, do testemunho, da notícia, do que se pode confirmar a partir de índices de realidade dos quais o objeto e a assinatura são primordiais. O detalhe é o elemento que transporta o leitor para o universo supostamente real de uma vida desconhecida, ou mesmo, poderíamos arriscar, que torna o morto vivo no decorrer da leitura.

18. Para Ricoeur (2012, tomo II, p. 174), a mediação da leitura proporcionaria a interação entre o mundo 
do texto e o do leitor. Essa refiguração seria uma "experiência virtual do ser no mundo proposta pelo texto" (idem), que permitiria uma "transcendência imanente" (idem).

19. "Publicar obituários nos jornais é uma forma pela qual os homens modernos lidam com a morte e defendem a vida, a publicação do obituário fornecendo um senso de finalidade, ao passo que celebrando os atributos mais valorosos do falecido, preservando e legitimando essas importantes características dos americanos ao longo da história da nação (tradução minha).

20. "Houve períodos de inatividade, como durante o período de guerra, como pioneiro, ou como quando ele sentiu que havia pintado demais. Mas seu obituário prematuro parece tê-lo estimulado, já que, após ter sua identidade estabelecida pela polícia local, ele sentiu que havia, de alguma forma, ressuscitado, tendo recebido uma segunda chance" (tradução minha).

21. Fowler fala, inclusive, em específicos "contratos de leitura" entre leitor e seu jornal. (2007, p. 22).

22. "Isso também molda as formas mais comuns de vidas breves existentes hoje: obituários e verbetes nos dicionários nacionais de biografias. Claro, as formas mais mundanas oferecem não mais que um registro, mas as melhores são informadas por um forte senso de por que 'essa' vida importou, geralmente junto com um senso maior de um contexto social e cultural. A disciplina da brevidade, a questão de por que uma vida particular merece consideração, traz um argumento lúcido à tona" (tradução e grifos meus).

23. Em uma das coletâneas, devotada a uma autor específico, caso de 52 McGs. (CLAHOUN, 2001), o prefácio é exemplar, ao chamar tais textos de uma "arte" escrita por "mestres" para iluminar a "vida ordinária" dos leitores (CLAHOUN, 2001, p.7).

24.É essa sedução involuntária que surge da leitura esteticamente orientada de um texto não-ficcional em prosa, afirma, a mais eficaz: se o texto é lido por sua conformação poética, esse texto é literatura. $\mathrm{Ou}$, ao menos, é lido de forma literária.

25. Mas tendemos a concordar com Compagnon (2003), quando afirma que "o critério de valor que inclui tal texto não é, em si mesmo, literário nem teórico, mas ético, social e ideológico, de qualquer forma extraliterário" (p. 34).”É uma sociedade que, pelo uso que faz dos textos, decide se certos textos são literários fora de seus contextos originais" (p. 44). "O contexto pertinente para o estudo literário de um texto literário não é o contexto de origem desse texto, mas a sociedade que faz dele um uso literário, separando-o de seu contexto de origem" (p. 45).
26. Pode-se até ir à Poética de Aristóteles para lembrar duas funções intrínsecas à literatura (ou mais especificamente à ficção) que podemos vislumbrar na leitura do obituário: a noção de katharsis (purgação, purificação da emoção) e a do prazer de aprender, ou "instruir agradando", na definição de Compagnon (2003, p. 35). Ambas, na tradição clássica, convergiriam para a formação de uma dóxa, um senso comum do que seria um valor literário do ponto de vista da recepção, assim como da ontologia do texto. Infelizmente não cabe aqui o extenso debate sobre estatuto epistemológico de um texto, literário ou não. Ou seja, como definir o obituário enquanto texto em relação ao regime de verdade que esse possui: o que é história, elenco de fatos pertencentes a uma dimensão assumidamente real, e o que é narrativa, história construída, enredo e estratégia de escrita.

\section{Referências}

ARFUCH, Leonor. O espaço biográfico: dilemas da subjetividade contemporânea. Tradução de Paloma Vidal. Rio de Janeiro: EdUERJ, 2010.

BARRY, Elizabeth. "Death and celebrity in eighteenthcentury British culture". International Journal of Cultural Studies, 2008. 259-275.

BARTHES, Roland. O rumor da língua. Trad. Mario Laranjeira. 2 ed. São Paulo: Martins Fontes, 2004.

BLANC, Dina. "Mallarmé On the Press and Literature: 'Étalages' and 'Le Livre, instrument spirituel. The French Review, Vol. 71, No. 3 (Feb., 1998) 414-424.

BRUNSKILL, Ian (edit). The Times Great Lives: A Century in Obituaries. Londres: HarperCollins Publishers, 2007.

BYTHEWAY, Bill, JOHNSON, Julia. "Valuing lives? Obituaries and the life course". Mortality, v. 1, n. 2, 1996. 219-234.

CLAHOUN, Chris (edit). 52 McGs.: The best obituaries from legendary New York Times reporter Robert McG. Thomas. New York: Scribner, 2001.

CODELL, Julie F. "Serialized artists' biographies: a culture industry in late Victorian Britain". Book History, v. 3, n. 1, 2000. 94-124.

COMPAGNON, Antoine. O Demônio da teoria: literatura e senso comum. Belo Horizonte : Editora UFMG, 2003.

DOSSE, François. O desafio biográfico: escrever uma vida. São Paulo: Edusp, 2009.

DOUGLAS, Ann. "Heaven our home: consolation literature in the Northern United States, 1830-1880". American Quarterly, v. 26, n. 5 (Death in America), Dec. 1974. 496-515. 
ECO, Umberto. Apocalípticos e integrados. São Paulo: Perspectiva, 1993.

FOWLER, Bridget. The obituary as collective memory. Nova York: Routledge, 2007.

FROW, John. "Reproducibles, rubrics, and everything you need: genre theory today". PMLA, v. 122, n. 5, 2007. 1626-1634.

GENETTE, Gérard. Fiction et diction. Paris: Seuil, 1991.

HALBWACHS, M. A memória coletiva. São Paulo: Centauro, 2006.

HUME, Janice. Obituaries in American Culture. University Press of Mississippi, 2000

JOLLES, André. As formas simples. São Paulo: Cultrix, 1976.

LARSON, R. Distinction and deference at death: a study of the obituary in the eighteenth-century English-American colonies and the early United States 1705-1795. Tese de doutorado - Emory University, 1996

LIMA, Luiz Costa. Trilogia do controle. Rio de Janeiro: Topbooks, 2007.

História, ficção, literatura. São Paulo: Companhia das Letras, 2006.

LJUNG, Magnus. "Newspaper genres and newspaper English". English Media Texts, Past and Present: Language and Textual Structure, 2000. 31-149.

MALLARMÉ, Stéphane. Igitur; Divagations; Un coup de dés. Présentée, établie et anotée par Bertrand Marchal. Paris: Gallimard, 2003.

MASSINGBERD, Hugh (edit). The Daily Telegraph book of obituaries: A celebration of eccentric lives. Londres: Pan Books, 1996.

OSBORNE, Phil, The Guardian book of obituaries. London: Atlantic Books, 2003.

RANCIÈRE, Jacques. A partilha do sensível: estética e política. São Paulo: EXO experimental org.; Ed. 34, 2005.

RICOEUR, Paul. Tempo e narrativa. São Paulo: wmfMartinsFontes, 2012.

- O si-mesmo como um outro. São Paulo: wmfMartinsFontes, 2014.

SARLO, Beatriz. Tempo passado, cultura da memória e guinada subjetiva. São Paulo e Belo Horizonte: Companhia das Letras e Editora da UFMG, 2005.

STARCK, Nigel. Writes of Passage: a comparative study of newspaper obituary practice in Australia, Britain and the United States. Flinders University, Adelaide. 2004.

VIEIRA, Willian. O obituário contemporâneo no jornal e nas coletâneas: uma discussão sobre gênero textual, biografia e sociedade. Dissertação - Mestrado em Estudos Culturais - Universidade de São Paulo, São Paulo, 2014).

VOGEL, Daisi. “A sobrevida do fait divers". Contracampo, n. 18, 2008. 135-148.

WALTER, John. "The utility of short lives". Biography, v. 29, n. 2, University of Hawai'i Press, 2006. 329 -337.

WIEVIORKA, Annette. L’Ėre du témoin. Paris: Plon, 1998.

Recebido em: 15/07/2016 Aceito em: 08/11/2016 